\title{
Application of Magnetic Nano-Immobilized Enzyme in Soybean Oil Degumming: Numerical Simulation in a Liquid-Solid MFB
}

\author{
Kuiren Chen, ${ }^{1}$ Tong Wang, ${ }^{1}$ Hong Wang, ${ }^{1}$ Haoyuan Geng, ${ }^{1}$ Jing Du, ${ }^{2}$ Dianyu Yu, \\ Walid Elfalleh $\left(\mathbb{D},{ }^{3}\right.$ Zouhaier Mehrez, ${ }^{4}$ and Liqi Wang ${ }^{5}$ \\ ${ }^{1}$ School of Food Science, Northeast Agricultural University, Harbin 150030, China \\ ${ }^{2}$ The Key Laboratory of Soybean Biology in Chinese Ministry of Education, Northeast Agricultural University, \\ Harbin 150030, China \\ ${ }^{3}$ Energy Water Environment and Process Laboratory (LR18ES35), National Engineering School of Gabes, University of Gabes, \\ Gabes 6072, Tunisia \\ ${ }^{4}$ Laboratory of Energy Heat and Mass Transfer (LETTM), Faculty of Sciences of Tunis, El Manar University, Tunis 2092, Tunisia \\ ${ }^{5}$ School of Computer and Information Engineering, Harbin University of Commerce, Harbin 150028, China
}

Correspondence should be addressed to Walid Elfalleh; walid.elfalleh@fst.rnu.tn

Received 3 January 2021; Revised 7 August 2021; Accepted 18 August 2021; Published 17 September 2021

Academic Editor: Fuguo Liu

Copyright (C) 2021 Kuiren Chen et al. This is an open access article distributed under the Creative Commons Attribution License, which permits unrestricted use, distribution, and reproduction in any medium, provided the original work is properly cited.

Using crude soybean oil (CSO) as fluid and nanomagnetic immobilized phospholipase C (PLC) as fluidizing particles, the Eulerian-Lagrangian fluid-particle two-phase flow model was used to numerically simulate the law of motion of fluidizing particles in the magnetic fluidized bed (MFB). The main parameters were obtained by numerical simulation based on the discrete element method (DEM). The nanomagnetic PLC in the MFB was optimal to the enzymatic reaction by limiting the iteration step size to $3 \times 10^{-5}$, the boundary condition to $20 \times 300 \mathrm{~mm}$, the opening rate to $37.5 \%$, the condition of CSO flow rate to $0.01 \mathrm{~m} / \mathrm{s}$, and the magnetic field strength to $0.02 \mathrm{~T}$. After $2.0 \mathrm{~h}$ of reaction, the amount of residual phosphorus in the oil was $55.73 \mathrm{mg} / \mathrm{kg}$, the content of 1,2-DAG was $1.42 \%$, and the nanomagnetic enzyme still had $97 \%$ relative activity. Hence, these optimal conditions can improve the efficiency and the stability of the nanomagnetic enzymatic reaction.

\section{Introduction}

Refining technology of edible oil refers to removing impurities, thereby improving the stability and safety of edible oil. Degumming is one of the crucial steps in refining. The primary purpose is to remove the phospholipid-based gums and reduce the impact on the remaining refining processes. Enzymatic degumming can efficiently remove the phospholipids in the CSO. Nowadays, enzymatic degumming commonly used phospholipases A1, A2, and C (PLA, $\mathrm{PLA}_{2}$, and PLC). Among them, $\mathrm{PLA}_{1}$ can specifically hydrolyze Sn1 in phospholipids, and hydrolysate lysophosphatidic acid has better hydrophilicity than other phospholipids. Immobilized in magnetic $\mathrm{Fe}_{3} \mathrm{O}_{4} / \mathrm{SiOx}$-g-P (GMA) nanoparticles, it can effectively remove nonhydrated phospholipids. Nevertheless, lysophospholipids undergo acyl transfer during $\mathrm{PLA}_{1}$ hydrolysis to reduce their enzymatic efficiency. $\mathrm{PLA}_{2}$ can hydrolyze the $\mathrm{Sn}-2$ acyl group of fatty acid esters. In previous studies, $\mathrm{PLA}_{2}$ was successfully immobilized on magnetic MPCSA, MCM, and $\mathrm{Fe}_{3} \mathrm{O}_{4} / \mathrm{SiOx}-\mathrm{g}-\mathrm{P}$ (GMA) nanoparticles [1]. $\mathrm{PLA}_{2}$ immobilization promotes the recovery of enzymes in the process of enzyme degumming. However, PLA 2 enzymatic activity is low, and the produced free fatty acid increases the acidity of oil [2]. PLC hydrolyzes the phospholipid ester bond at the Sn-3 position of phospholipids to form 1,2-diacylglycerol (1,2-DAG) and phosphate monoester [3] and 1,2-DAG is retained in fats and oils. PLC showed a good application prospect in enzymatic degumming. However, free PLC still has many disadvantages, such as low yield and cannot be reused for degumming. The emergence of immobilized enzyme technology has solved the above problems. At this stage, the 
immobilized enzyme mainly refers to immobilizing the enzyme particle on a carrier to improve its stability and catalytic effect. In recent years, magnetic nanoparticles became much more well known to the public. $\mathrm{Fe}_{3} \mathrm{O}_{4}$ magnetic nanoparticles have attracted much attention in their applications because they have the characteristics of nanomaterials as well as the superparamagnetism and high susceptibility of magnetic materials [3,4]. The magnetic polymer carrier prepared with $\mathrm{Fe}_{3} \mathrm{O}_{4}$ has strong magnetic responsiveness. $\mathrm{Fe}_{3} \mathrm{O}_{4}$ can be quickly separated from other products under the action of an external magnetic field. At the same time, $\mathrm{Fe}_{3} \mathrm{O}_{4}$ surface can be modified to carry various functional groups [5] so that $\mathrm{Fe}_{3} \mathrm{O}_{4}$ has strong adsorption capacity and good separation characteristics and it is more suitable for magnetic immobilization of enzymes [6]. Due to the porous structure of nanomagnetic particles, smaller particles have a larger specific surface area and higher enzyme content per unit mass of particles [7, 8]. After the free PLC is attached to the magnetic carrier, it has the characteristics of magnetic response under the action of the magnetic field. Consequently, CSO can be degummed in a magnetic fluidized bed (MFB). The magnetic particles in the MFB are locked in the magnetic field region, and the reaction substrate can be in contact with the magnetic particles without interruption and quickly separated [9]. Under the action of an appropriate external magnetic field and liquid flow rate, the magnetic particles in the MFB will be in regular fluidization. Regular fluidization can increase the mass and heat transfer rate of the fluid in the bed, thereby increasing the catalytic reaction speed [10]. Therefore, the MFB under the action of the magnetic field can be controlled by the direction and the intensity of the magnetic field. Therefore, achieving the ideal fluidization state of the liquid-solid twophase inside the MFB provides a continuous degumming reaction. To optimize the enzymatic hydrolysis reaction of an MFB, it is necessary to study the movement law of magnetically immobilized PLC. In recent years, computer numerical simulation technology has gradually become one of the primary methods to study the flow patterns of relatively larger particles in various reactors. However, the study of three-dimensional numerical simulation technology of nanoscale magnetic particles in MFB is limited. 3D numerical simulation technology saves much work compared with experimental research, correspondingly shortens the experimental cycle, and considerably saves the experimental expenses. Moreover, it is difficult to see the pattern of motion and distribution of nanosolid particles in the MFB directly. So, it is imperative to perform detailed simulation on the MFB first. Computational fluid dynamic (CFD) models are usually used to solve and analyze the state of complex phases in an MFB [11].

At present, the mathematical model of liquid-solid twophase flow mostly adopts the Eulerian-Lagrangian method. Eulerian-Lagrangian method regards the main phase as continuous phase and the sparse phase as discrete particles [12]. The main phase uses the Euler method, while the discrete phase uses the Lagrange method for particle tracking. This is the so-called Euler-Lagrange model. In this model, the volume fraction of discrete phase should not exceed 15\% [13]. The discrete phase and the main phase have their own pressure, viscosity, and turbulent diffusion sparsity parameters, and the trajectory of discrete phase particles is investigated in the Lagrange coordinate system [14]. The model can analyze the interaction between particles and droplets and the complex interaction between fluids in detail. This model can avoid the application of a large number of empirical relations and the diffusion problem of discrete phase numerical solution [15]. Although the amount of calculation is huge, the accuracy is higher than that of the Euler model. The results show that the discrete phase model can simulate the liquid-solid two-phase flow more accurately and track the motion of solid particles in the continuous phase.

For CFD simulation tools, many kinds have appeared. Among them, the OpenFOAM simulation technology has gradually become more developed, which can effectively solve the problems in constructing models, depicting grids, solving calculations, extracting data, analyzing data, and visual processing $[16,17]$. Previous research established a two-dimensional numerical model using the discrete element method with CSO as the substrate [18]. The effects of magnetic field strength and flow on the motion and distribution of $\mathrm{PLC}-\mathrm{Fe}_{3} \mathrm{O}_{4} / \mathrm{SiOx}$-g-P (GMA) particles under the MFB were studied providing an optimum of the degumming of oil in MFB.

In the current research, single MFB was prepared and connected in series into a multistage liquid-solid MFB circulating degumming system. The optimal parameters of computer numerical simulation obtained by OpenFOAM software were used to study the effects of degumming time, $\mathrm{pH}$ value, temperature, and the number of nanomagnetic enzymes on the residual phosphorus content of CSO in a multistage liquid-solid MFB. In this context, the current study aims to increase the enzymatic hydrolysis efficiency and stability and also to improve the degumming effect of CSO without mechanical stirring. The main goal is to achieve the continuous reaction of magnetic particles in MFB and provide a theoretical basis for the continuous removal of phospholipids in CSO.

\section{Materials and Methods}

2.1. Materials and Reagents. PLC (enzymatic activity 17000 $\mathrm{U} / \mathrm{g}$ (purchased from DSM; CSO $(800 \mathrm{mg} / \mathrm{kg}$ phosphorus, $0.81 \%$ phosphatidylcholine (PC), $0.37 \%$ phosphatidylethanolamine (PE), $0.37 \%$ phosphatidylinositol (PI), $0.18 \%$ phospholipid acid (PA), 0.30\% 1, 2-diacylglycerol (DAG)) was supplied by Jiusan Cereals and Oils Industry Group Co., Ltd. Other chemicals and solvents were of analytical grade and were purchased from Sinopharm Chemical Reagent Co., Ltd.

2.2. Preparation of $\mathrm{PLC}_{-} \mathrm{Fe}_{3} \mathrm{O}_{4} / \mathrm{SiOx}-\mathrm{g}-\mathrm{P}$ (GMA). $\mathrm{Fe}_{3} \mathrm{O}_{4} / \mathrm{SiOx}-\mathrm{g}-\mathrm{P}$ (GMA) PLC particles were prepared according to Jiang et al. [18]. $\mathrm{Fe}_{3} \mathrm{O}_{4} / \mathrm{SiOx}-\mathrm{g}-\mathrm{P}$ (GMA) support $(1.0 \mathrm{~g})$ was dissolved in $0.1 \mathrm{~mol} / \mathrm{L}$ phosphate buffer solution with $\mathrm{pH} 6$ for $24 \mathrm{~h}$. After magnetic separation, 
$0.02 \mathrm{~g} / \mathrm{mL}$ PLC solution was added and stirred at $55^{\circ} \mathrm{C}$ for $5 \mathrm{~h}$. Finally, the magnets were separated and washed with phosphate buffer solution three times to obtain $\mathrm{PLC}-\mathrm{Fe}_{3} \mathrm{O}_{4} /$ SiOx-g-P (GMA) particles. After drying, they were stored in the refrigerator at $4^{\circ} \mathrm{C}$, where the amount of enzyme was within the unit mass of the carrier contains.

\subsection{Multistage MFB Cycle Degumming Process Design.} Since the degumming reaction is a complex process, the variables and reaction conditions need to be dynamically controlled. Therefore, based on the MFB of the reaction main unit, a liquid-solid two-phase MFB degumming reaction system is established, and the ordered connection of each part is designed. The degumming reaction process flow chart of PLC- $\mathrm{Fe}_{3} \mathrm{O}_{4} / \mathrm{SiOx}$-g-P (GMA) is presented in Supplementary Figure 1.

The CSO is introduced into the MFB degumming reaction system, and the specific procedure is as follows: the CSO is pumped into the liquid buffer tank (3) from the oil storage tank (1) through the constant flow pump (5), and the valve of the clean oil tank (4) is closed. In the mixer (6), a certain proportion of PLC-Fe3O4/SiOx-g-P (GMA) particles are mixed, and the flow rate is stably input into the MFB (8) through the flow meter (7), and an MFB degumming reaction is performed. Finally, the degumming oil enters the liquid temporary storage tank (11). At the same time, the valve connected to the liquid circulation tank (2) is opened for cyclic degumming and enzymatic hydrolysis. The fat is extracted in real time to determine the phosphorus content until the corresponding standard is reached, and the valve of the recovery oil tank (13) is opened, and the mixture of the degummed oil and the phospholipase is recovered. The MFB continuous enzymatic degumming process is achieved.

\section{4. $\mathrm{PLC}-\mathrm{Fe}_{3} \mathrm{O}_{4} / \mathrm{SiOx}$-g-P (GMA) Degumming Process}

\subsection{1. $\quad P L C-\mathrm{Fe}_{3} \mathrm{O}_{4} / \mathrm{SiOx}$-g-P (GMA) Degumming.} Accurately $300 \mathrm{~g}$ of CSO was placed in a $500 \mathrm{~mL}$ Erlenmeyer flask, heated to $80^{\circ} \mathrm{C}$ in water bath, and $0.36 \mathrm{~mL} 45 \%$ citric acid was added for acid-treatment during $20 \mathrm{~min}$ at $80^{\circ} \mathrm{C}$ under $100 \mathrm{r} / \mathrm{min}$. Then, cooled to $50^{\circ} \mathrm{C}$, and $4 \% \mathrm{NaOH}$ solution was added to adjust the $\mathrm{pH}$ to 5.0 . Next, $2 \%$ distilled water and $30 \mathrm{mg} / \mathrm{kg}$ PLC- $\mathrm{Fe}_{3} \mathrm{O}_{4} / \mathrm{SiOx}-\mathrm{g}-\mathrm{P}$ (GMA) were, respectively, added (the ratio of enzyme to oil quality and enzyme water 50 times diluted). The enzymatic degumming test was carried out for $45 \mathrm{~min}$ at a stirring speed of $50 \mathrm{r} / \mathrm{min}$. The samples were inactivated in hot water at $90^{\circ} \mathrm{C}$ for $10 \mathrm{~min}$ and centrifuged at $3000 \mathrm{r} / \mathrm{min}$ for $15 \mathrm{~min}$.

2.4.2. $\mathrm{MFB} \quad \mathrm{PLC}-\mathrm{Fe}_{3} \mathrm{O}_{4} / \mathrm{SiOx}$ - $\mathrm{g}-\mathrm{P}$ (GMA) Degumming. The predegumming treatment is the same as in (1). After adjusting the $\mathrm{pH}$, it is passed into the MFB system for degumming test.

2.5. Study on the Effect of Nanomagnetic Enzyme on Degumming of CSO. The effect of nanomagnetic enzyme on the degumming of CSO under different environmental conditions was conducted according to Jiang et al. [18]. Batch degumming was compared with multistage cyclic degumming in MFB.

\subsection{Detection Method}

2.6.1. Determination of Phosphorus Content. Phosphorus content was determined by the AOCS method of 12-55 [19]. In short, $0.4387 \mathrm{~g}$ of potassium dihydrogen phosphate was accurately weighed and diluted to $1000 \mathrm{~mL}$, which was the standard stock solution with phosphorus content of $0.1 \mathrm{mg} /$ $\mathrm{mL} ; 10 \mathrm{~mL}$ of standard stock solution was diluted to $100 \mathrm{~mL}$, which was the standard phosphate solution with a phosphorus content of $0.01 \mathrm{mg} / \mathrm{mL} .0,1,2,4,6$, and $8 \mathrm{~mL}$ phosphate standard solution with a phosphorus content of $0.01 \mathrm{mg} / \mathrm{mL}$ was added into a $50 \mathrm{~mL}$ colorimetric tube, respectively, and distilled water was added to make up to $10 \mathrm{~mL}$. Meanwhile, $8 \mathrm{~mL}$ of hydrazine sulfate solution $(0.015 \%)$ and $2 \mathrm{~mL}$ of $2.5 \%$ sodium molybdate dilute sulfuric acid solution were added to the colorimetric tube and heated in boiling water bath for $10 \mathrm{~min}$. After cooling to room temperature and let stand for $10 \mathrm{~min}$, the absorbance of the solution was measured at $650 \mathrm{~nm}$. The regression equation was $y=5.4072 x+0.0061$ and $r=0.9997$, with the absorbance as ordinate and the phosphorus content $(0.00,0.01,0.02$, $0.04,0.06,0.08 \mathrm{mg}$ ) as abscissa. The test oil sample ( $3 \mathrm{~g})$ was accurately weighed, and $\mathrm{ZnO}(0.5 \mathrm{~g})$ was added and burned in a muffle furnace at $550-600^{\circ} \mathrm{C}$ to obtain the ash, then dissolved completely with $10 \mathrm{~mL}$ hydrochloric acid solution (the ratio of concentrated hydrochloric acid to water is $1: 1$ ) and heated to boiling. The remaining solution was neutralized with $50 \%$ sodium hydroxide solution until turbidity appears. Hydrochloric acid solution was slowly added to dissolve all zinc oxide precipitates. The sample is cooled to room temperature and diluted in a $100 \mathrm{~mL}$ volumetric flask. As in the standard curve drawing, $10 \mathrm{~mL}$ of the measured solution was injected into $50 \mathrm{~mL}$ colorimetric tube, and $8 \mathrm{~mL}$ of hydrazine sulfate solution $(0.015 \%)$ and $2 \mathrm{~mL}$ of $2.5 \%$ sodium molybdate dilute sulfuric acid solution were added to the colorimetric tube and heated in boiling water bath for $10 \mathrm{~min}$. After cooled to room temperature and let stand for $10 \mathrm{~min}$, the absorbance of the solution was measured at $650 \mathrm{~nm}$. The phospholipid content in the sample was calculated according to the following equation:

$$
X=\frac{p V_{1}}{V V_{2}} \times 26.31,
$$

where $X$ : phospholipid content $(\mathrm{mg} / \mathrm{mL}) ; P$ : the phosphorus content of the tested solution obtained from the standard curve $(\mathrm{mg}) ; V$ : volume of oil sample $(\mathrm{mL}) ; V_{1}$ : volume of sample diluted after ashing $(\mathrm{mL}) ; V_{2}$ : volume of the solution to be measured in colorimetry $(\mathrm{mL}) ; 26.31$ : each milligram of phosphorus is equivalent to milligrams of phospholipids.

2.6.2. PLC Enzyme Activity Determination. The activity of the PLC was determined by the method of Jiang et al. [20]. $250 \mathrm{mmol} / \mathrm{L}$ tris- $\mathrm{HCl}$ buffer of $\mathrm{pH} 7.2,1 \mathrm{mmol} / \mathrm{L} \mathrm{ZnCl} 2$, and $10 \mathrm{mmol} / \mathrm{L} \mathrm{p}$-NPPC were mixed in $2 \mathrm{~mL}$ reaction system. 
The mixture was incubated for $5 \mathrm{~min}$ at $37^{\circ} \mathrm{C}$, and an appropriate dilution of the enzyme was added to be tested. $100 \mu \mathrm{L}$ of the solution was kept to react for $30 \mathrm{~min}$, and the absorbance was measured at a wavelength of $410 \mathrm{~nm}$. The PLC enzyme activity is defined as the amount of enzyme required to produce $1 \mathrm{nmol}$ of p-nitrophenol per minute at $\mathrm{pH} 7.2$ and $37^{\circ} \mathrm{C}$ as one enzyme activity unit (U). The PLC enzyme activity was calculated according to the following equation:

$$
\operatorname{activity}\left(\frac{U}{m}\right)=1.3636 \times 10^{3} \times \frac{A}{t},
$$

where $1.3636 \times 10^{3}$ : reaction conversion factor; $A$ : absorbance; $T$ : reaction time, $\min$.

2.6.3. Detection of Iron in Fats and Oils. Oil samples were taken at the exit of any MFB, and the iron content was determined according to Ravasi et al. [21].

\subsection{Numerical Simulation of Nanomagnetic Enzyme in Liquid-Solid MFB}

2.7.1. MFD Model and Nanomagnetic Enzyme Characteristics. The size of the inner diameter of the MFB reactor to be designed is $\Phi 20 \times 300 \mathrm{~mm} \mathrm{(MFB}$ bed width $\times$ height), and $8.67 \times 10^{-3}$ g nanomagnetic enzyme was added into the MFB reactor and the number of particles, which selected 3000 nanomagnetic enzyme particles as the research object; the three-dimensional cylinder with a diameter of $11 \mu \mathrm{m}$ and a height of $22 \mu \mathrm{m}$ area of model was designated for the computer simulation as presented in Supplementary Figure 2.

2.7.2. Mathematical Formulation. The main mathematical solution model is the Euler-Lagrangian model which considers liquid-phase oil as continuous phase and nanomagnetic enzyme as discrete phase $[14,15]$ simulation based on MP-PIC discrete control equation, while the equation of motion of two-phase flow adopts Navier-Stokes and refers to $\mathrm{Yu}$ et al. [22]. A longitudinal magnetic field was introduced to study the distribution, velocity, and flow of the nanomagnetic enzyme particles at this time. The governing equations are as follows:

(i) Liquid-phase equations:

(i) Mass conservation (continuity) equation:

$$
\frac{\partial\left(\varepsilon_{l} \rho_{l}\right)}{\partial t}+\nabla \cdot\left(\rho_{l} \varepsilon_{l} u_{l}\right)=0 .
$$

Here, the concentration, density, and velocity of the liquid phase are, respectively, $\varepsilon_{l}, \rho_{l}$, and $v_{l}$. (ii) Momentum conservation equation:

$$
\frac{\partial\left(\varepsilon_{l} \rho_{l} v_{l}\right)}{\partial_{t}}+\nabla \cdot\left(\varepsilon_{l} \rho_{l} v_{l} v_{l}\right)=\varepsilon_{l} \nabla \cdot \tau_{l}-\varepsilon_{l} \nabla p+\varepsilon_{l} \rho_{l} g-\beta\left(v_{l}-v_{s}\right)
$$

(i) In (4), $g$ is the gravity acceleration; $\rho$ is the liquid pressure; $\beta$ is the drag coefficient of the liquid-solid two phase; and $\tau_{1}$ is the liquid-phase stress tensor, which can be calculated by the following formula:

$$
\tau_{l}=\mu_{l}\left[\nabla v_{l}+\left(\nabla v_{l}\right)^{T}\right]-\frac{2 \mu_{l}\left(\nabla \cdot v_{l}\right) I}{3} .
$$

(ii) Solid-phase equations: (i) Mass conservation equation:

$$
\frac{\partial\left(\varepsilon_{s} \rho_{s}\right)}{\partial t}+\nabla \cdot\left(\rho_{s} \varepsilon_{s} u_{s}\right)=0
$$

Here, the concentration, density, and velocity of the solid phase are, respectively, $\varepsilon_{s}, \rho_{s}$, and $v_{s}$.

(i) Momentum conservation equation:

$$
\frac{\partial\left(\varepsilon_{s} \rho_{s} v_{s}\right)}{\partial t}+\nabla \cdot\left(\varepsilon_{s} \rho_{s} v_{s} v_{s}\right)=\varepsilon_{s} \nabla \cdot \tau_{s}+\varepsilon_{s} \rho_{s} g-\varepsilon_{s} \nabla p+\beta\left(v_{l}-v_{s}\right)
$$

Here, $g$ is the acceleration of gravity; $\beta$ is the drag coefficient of liquid-solid two-phase; and $\tau_{s}$ is the liquid-phase stress tensor, which can be calculated by the following formula:

$$
\tau_{s}=\left(\xi_{s} \nabla \cdot v_{s}-p_{s}\right) I+\mu_{s}\left\{\left[\nabla v_{s}+\left(\nabla v_{s}\right)^{T}\right]-\frac{2\left(\nabla \cdot v_{s}\right) I}{3}\right\} .
$$

Here, the pressure $p_{s}$, the viscosity $\xi_{s}$ and the dynamic viscosity $\mu_{s}$ are given by the following formulations:

$$
\begin{aligned}
& p_{s}=\varepsilon_{s} \rho_{s} \theta+2 \rho_{s}(1+e) \varepsilon_{s}^{2} g_{0} \theta, \\
& \xi_{s}=\frac{4}{3} \varepsilon_{s}^{2} \rho_{s} d_{s} g_{0}(1+e)\left(\frac{\theta}{\pi}\right)^{1 / 2},
\end{aligned}
$$


$\mu_{s}=\frac{4}{5} \varepsilon_{s}^{2} \rho_{s} d_{s} g_{0}(1+e) \sqrt{\frac{\theta}{\pi}}+\frac{10 \rho_{s} d_{s} \sqrt{\pi \theta}}{96(1+e) \varepsilon_{s} g_{0}}\left[1+\frac{4}{5} g_{0} \varepsilon_{s}(1+e)\right]^{2}$.

In equations (9)-(11), $e$ is the solid-phase collision return coefficient and $g_{0}$ refers to the contact probability used to correct the discrete phase and is specifically determined by the Bagnold equation [23].

The drag coefficient of the liquid-solid two phase $\beta$ can be calculated by referring to the Gidaspow formula as follows:

$$
\begin{cases}\beta=150 \frac{\varepsilon_{s}\left(1-\varepsilon_{l}\right) \mu_{l}}{\varepsilon_{l} d_{s}^{2}}+1.75 \frac{\rho_{l} \varepsilon_{s}}{d_{s}}\left|v_{l}-v_{s}\right|, & \varepsilon_{s} \leq 0.8, \\ \beta=\frac{3 C_{d} \varepsilon_{l} \varepsilon_{s} p_{l}\left|v_{l}-v_{s}\right|}{4 d_{s}}, & \varepsilon_{s} \geq 0.8 .\end{cases}
$$

coefficient $C_{d}$ in equation (12) which depends on the Reynolds number can be estimated by using the following formulation:

$$
\begin{cases}C_{d}=\frac{24}{R_{e}}\left(1+0.15 R_{e}^{0.687}\right), & R_{e} \leq 1000, \\ C_{d}=0.44, & R_{e} \geq 1000 .\end{cases}
$$

Reynolds number $R_{e}$ is given as follows:

$$
R_{e}=\frac{d_{s} \varepsilon_{l} \rho_{l}\left|v_{l}-v_{s}\right|}{\mu_{l}} .
$$

(1) Magnetic Field Correlation Equation. After the introduction of the magnetic field, each solid phase (particle) needs to be subjected to force analysis [24], that is, for particle $\boldsymbol{i}$, obtained by Newton's second law:

$$
m_{i} \frac{\mathrm{d} v_{i}}{\mathrm{~d} t}=m_{i} g-V_{p} \nabla P+f_{d i}+f_{m i}+\sum_{j=1}^{N}\left(f_{l j}+f_{c j}+F_{m j}\right),
$$

$$
I_{p} \frac{\mathrm{d} \omega_{i}}{\mathrm{~d} t}=\sum_{j=1}^{N} T_{p i j}
$$

Here, $f_{m i}$ denotes the virtual mass force acting on the particle $i$. Among them, $f_{d}$ is indicating drag and considers the following factors:

$$
f_{d}=\frac{\beta V_{p}}{1-\varepsilon_{l}}\left(u_{l}-u_{p}\right) \text {, }
$$

where $f_{c j}$ is a contact force applied on the magnetized nanoparticle enzyme due to the collision between the particles. $f_{l j}$ represents the lubricating force applied on the non-nanomagnetic enzyme particle by the oil.

In equations (13) and (14), $m_{i}, v_{i}$, and $V_{p}$ are the mass, velocity, and volume of the solid phase, respectively. $T_{p}, I_{p}$, and $\omega$ are the torque, moment of inertia, and angular velocity of the component in the tangential direction of the force tangential direction.

In equation (15), $\varepsilon_{l}$ and $\beta$ are the liquid-phase volume and the momentum transfer coefficient, respectively. Under the influence of a magnetic field, the nanomagnetic enzyme particle is subjected to the effect of a magnetic force which is composed of two components [24, 25]. It is written as follows:

$$
F_{m}=F_{m e}+F_{m i},
$$

where $F_{m e}$ represents the external applied magnetic force and $F_{m i}$ denotes the magnetic force due the magnetic interaction between the particles. As an important factor, the susceptibility coefficient needs to be considered separately [26]. Therefore, the susceptibility of the MFB as a whole and the susceptibility of the discrete phase need to be closely related. They are related by the following formulation:

$$
\frac{x}{x+3}=\varepsilon_{s} \frac{x_{p}}{x_{p}+3} \text {. }
$$

Here, $x_{p}$ represents the solid-phase magnetic susceptibility.

$$
F_{m e}=V_{p} x_{e} M H \nabla H,
$$

where $M$ is the magnetic moment of the fluid particle and $H$ denotes the magnetic field.

The magnetic interactions between nanomagnetic enzyme particles are presented in Supplementary Figure 3, where $r$ denotes the distance between particles enzyme A and $\mathrm{B}$ and $B_{0}$ is the intensity of the applied uniform magnetic field. $m_{a}$ and $m_{b}$ are the magnetic moment of nanoparticles $\mathrm{A}$ and $\mathrm{B}$, respectively [27]. $F_{r}$ represents the radial component and $F_{\theta}$ represents the orthoradial component of the interparticle magnetic force $F_{m i}$ applied by particle $\mathrm{A}$ on particle $\mathrm{B}$.

The two components $F_{r}$ and $F_{\theta}$ are obtained by projecting the $F_{m i}$ force in the polar base $(r, \theta)$. They are given by the following expressions:

(i) Radial component:

$$
F_{r}=-\frac{\mu_{0}}{4 \pi}\left\{\frac{m^{2}}{r^{3}}[-6 \cos (\theta-\gamma) \sin (\theta-\gamma)] \frac{\partial \gamma}{\partial r}+\left[1-3 \cos ^{2}(\theta-\gamma)\right] \cdot\left(-\frac{3 m^{2}}{r^{4}}+\frac{2 m}{r^{3}} \frac{\partial m}{\partial r}\right)\right\}
$$


(ii) Orthoradial component:

$$
F_{\theta}=2 m\left[1-3 \cos ^{2}(\theta-\gamma)\right] \frac{\partial m}{\partial \theta}-\frac{\mu_{0}}{4 \pi r^{4}}\left\{6 m^{2} \cos (\theta-\gamma) \sin (\theta-\gamma)\left(1-\frac{\partial \lambda}{\partial \theta}\right)\right\}
$$

The variations of the magnetic moment $m$ of the enzyme particle in the radial and orthoradial directions are given by the two following equations:

$$
\begin{aligned}
& \frac{\partial \gamma}{\partial \theta}=\frac{2\left(3\left(x_{e} V_{p} / 8 \pi r^{3}\right) \sin 2 \theta\right)^{2}+6\left(x_{e} V_{p} / 8 \pi r^{3}\right) \cos 2 \theta\left[1+\left(x_{e} V_{p} / 8 \pi r^{3}\right)(3 \cos 2 \theta-1)\right]}{\left[1+\left(x_{e} V_{p} / 8 \pi r^{3}\right)(3 \cos 2 \theta-1)\right]^{2}+\left(3\left(x_{e} V_{p} / 8 \pi r^{3}\right) \sin 2 \theta\right)^{2}}, \\
& \frac{\partial m}{\partial \theta}=\frac{x_{e} V_{p} B}{\mu_{0}\left[\left(1-\left(x_{e} V_{p} / 8 \pi r^{3}\right)\right) \cos \gamma-3\left(x_{e} V_{p} / 8 \pi r^{3}\right) \cos (2 \theta-\gamma)\right]^{2}} .
\end{aligned}
$$

The two angles $\gamma$ and $\theta$, indicated in Supplementary

Figure 3, are related by the following formulation:

$$
\frac{\partial \gamma}{\partial \theta}=\frac{2\left(3\left(x_{e} V_{p} / 8 \pi r^{3}\right) \sin 2 \theta\right)^{2}+6\left(x_{e} V_{p} / 8 \pi r^{3}\right) \cos 2 \theta\left[1+\left(x_{e} V_{p} / 8 \pi r^{3}\right)(3 \cos 2 \theta-1)\right]}{\left[1+\left(x_{e} V_{p} / 8 \pi r^{3}\right)(3 \cos 2 \theta-1)\right]^{2}+\left(3\left(x_{e} V_{p} / 8 \pi r^{3}\right) \sin 2 \theta\right)^{2}}
$$

2.7.3. Numerical Procedure and Meshing Choice. The above governing equations are solved by using the discrete element method (DEM) [28, 29]. The CSO is used as the liquid-phase fluid, and the nanomagnetic enzyme particles are used as the solid phase. Since the particles are too small, the particle cloud calculation method is adopted, and the number of particle clouds is regarded as the number of particles in the simulation process. The relevant physical properties and initial parameters of the MFB simulation are shown in Table 1.

The solver in OpenFOAM v1706 is used to solve the problem. In the simulation process, 666,600-time steps are calculated with an iteration step of $3 \times 10^{-5} \mathrm{~s}$, and the total calculation time is $19.99 \mathrm{~s}$. Computer configuration: Intel Pentium Dual Core E5300 2.6 GHz dual-core processor, 4G memory, and each data operation time is about $96 \mathrm{~h}-144 \mathrm{~h}$ range.

The three-dimensional cylindrical MFB model was established by using OpenFOAM preprocessing software. The MFB model was meshed by Block Mesh. The wall of the MFB was mainly divided by rectangular grid, while the bed top and bottom as the connecting part of the wall were divided by a circular mesh. The grid size is determined based on the retention rate of the nanomagnetic enzyme. The grid model is shown in Figure 1.

2.7.4. Pore Size of Porous Plate. The main function of the porous plate in the MFB is to achieve a better fluidization state of the internal particles by changing the liquid flow field. By adjusting the ratio of the opening area to the whole plate, the specifications of the porous plates with different opening ratios are shown in Figure 2.

2.7.5. Magnetic Field Strength. The Hall magnetic intensity detector is used to measure the field strength of different parts in the MFB, and the output signal is output to the $\mathrm{V} / \mathrm{F}$ converter. The microprocessor performs the counting and calculation of the output signal and converts the analog value into a numerical value at each moment. The measurement results displayed on the screen are accurate [30]. The current is used to generate the magnetic field. The relationship between the current intensity and the magnetic field strength is shown in Table 2. The magnetic field strength $0 \sim 0.03 \mathrm{~T}$ corresponds to the matching current. The Hall magnetic field strength detection tool is used to detect the magnetic field strength. The strength of the magnetic field can be changed according to the strength of the incoming current (Table 2).

2.8. Data Processing. Three experiments were carried out, and all values were presented as mean \pm standard deviation. Data processing and plotting was performed using Origin 8.5 using Design Expert 8.0.6 to optimize the degumming process parameters and SPSS software for data, statistics, and correlation analysis. 
TABLE 1: The setting of the initial conditions of the simulation.

\begin{tabular}{lc}
\hline Name & Parameter \\
\hline Bed width $\times$ bed height & $20 \times 300 \mathrm{~mm}$ \\
Liquid-phase density & $920 \mathrm{~kg} / \mathrm{m}^{3}$ \\
Solid-phase initial stack height & $2 \mathrm{~mm}$ \\
Solid-phase density & $5170 \mathrm{~kg} / \mathrm{m}^{3}$ \\
Number of solid phases (particle cloud) & 1600 \\
Solid-phase friction coefficient & 0.8 \\
Solid-wall friction coefficient & 0.5 \\
\hline
\end{tabular}

\section{Results and Discussion}

3.1. Effect of Grid Scale on Nanomagnetic Enzyme Distribution. Figure 3 shows the influence of three different grid sizes on the distribution of nanomagnetic enzymes at a certain height inside the MFB device. According to Figure 3(a), the content of nanomagnetic enzyme is reduced in the middle region, but higher in the vicinity of the inner wall of the device. At the same time, different grid sizes have little effect on the overall nanomagnetic enzyme distribution in the middle area of the MFB device.

It can be noticed from Figure 3(b) that when the number of grids is small $(10 \times 200)$, the polyline of the nanomagnetic enzyme distribution state shows a significant oscillation phenomenon, making the calculation inaccurate [31, 32]. This is mainly because grid points are relatively far away from each other. When the number of divisions is large $(20 \times 300$ and $30 \times 400)$, the nanomagnetic enzyme distribution tends to be flat. Therefore, in consideration of the calculation time, a grid size of $20 \times 300 \mathrm{~mm}$ is used in this study.

3.2. Influence of the Porosity of the Multiwell Plate on the Distribution of Nanomagnetic Enzymes. Figures 4(a) and 4(b) show four different perforated plates whose opening ratio is proportional to the number of openings. In the middle area of the MFB device, the flow rate of the CSO is $150 \mathrm{~mm} 0.01 \mathrm{~m} / \mathrm{s}$, with reference to the effect of the pore size of the multiwell plate designed on 2.3.5 on the distribution of nanomagnetic enzymes. The porosity of different multiwell plates has a significant effect on the nanomagnetic enzyme distribution. When the open porosity is $22.5 \%$, the nanomagnetic enzyme distribution is unstable, and the calculation result of its unevenness is high. The reason may be that the open porosity of the perforated plate is low, and the CSO is formed when it enters the bed through the perforated plate. In the spouted bed, a strong impact on the nanomagnetic enzyme phase is shown, making the nanomagnetic enzyme phase moving disorderly. When the open porosity is $30 \%$, the uniformity of the nanomagnetic enzyme distribution has been significantly improved. The unevenness greatly decreased, but the nanomagnetic enzyme distribution at the same bed height is still unstable. When the open porosity is $37.5 \%$, the nanomagnetic enzyme particle unevenness is low, and its nanomagnetic enzyme is at the axial height of $150 \mathrm{~mm}$. The distribution state is relatively stable. When the open porosity is $45 \%$, due to the large open porosity, the expansion height of the bed layer on the porous plate increases, and the nanomagnetic enzyme particle distribution becomes unstable again. The nonuniformity of the porosity of different perforated plates is compared. When the porosity is $30 \%$ to $45 \%$, the nonuniformity is low. Combining with the uniform distribution curves of the nanomagnetic enzyme distribution in Figure 5(a), it can be concluded that when the rate is $37.5 \%$, the magnetic phase distribution effect is the finest.

3.3. Influence of CSO Flow Rate on the Distribution of Nanomagnetic Enzymes. Figure 5 shows the effects of the three types of CSO flow velocity on the distribution of nanomagnetic enzymes at different axial heights inside the MFB device. According to Figure 5(a), the nanomagnetic enzyme particles have different nanomagnetic enzyme distribution states at the same height under the conditions of different CSO flow rates. When the flow rate of the CSO is slow, the content of the nanomagnetic enzyme is higher near the entrance of the CSO. This is mainly due to the larger effect of the nanomagnetic enzyme because of gravity, which is prone to accumulation. The nanomagnetic enzyme content at the same position is reduced, so the increase of the flow velocity of the CSO increases with the height of the bed expansion, so that the nanomagnetic enzyme particles move to the upper part of the bed [33]. Figure 5(b) shows that when the internal height of the intercepted MFB device increases to near the outlet of the CSO, the velocity of the CSO increases. Accordingly, its ability to carry nanomagnetic enzyme particles is enhanced. When the velocity of CSO decreases, the height of the corresponding bed expansion decreases, and the nanomagnetic enzyme content decreases. At the same time, when the flow rate of the CSO is low, the nanomagnetic enzyme particles have relatively uniformly distributed inside the MFB device. Therefore, to select the optimal CSO flow rate, further consideration must be given to the movement state of the nanomagnetic enzyme.

3.4. Effect of CSO Flow Rate on Nanomagnetic Enzyme Movement Speed. Figure 6 shows the particle velocity vector diagram of different flow velocity of CSO. When the fixed field strength is $0.02 \mathrm{~T}$, the velocity of different CSO is used as the initial parameter. According to the simulation results, when the same physical time is intercepted for $6 \mathrm{~s}$, the direction of the particle is represented by the direction of the arrow, and the color indicates the speed value to investigate the velocity change of nanomagnetic enzyme particles at a height of $150 \mathrm{~mm}$ inside the MFB device. The liquid flow velocity needs to be selected according to the fluidization state of the internal suspended magnetic particles. When the flow rate of the CSO is $0.001 \mathrm{~m} / \mathrm{s}$, the speed of the nanomagnetic enzyme particles is stable within the range of 0.005 to $0.015 \mathrm{~m} / \mathrm{s}$. From the direction of particle speed, although the particles move up and down the wall along the regular middle part of the MFB, the velocity change value is smaller than the flow rate of the CSO $0.01 \mathrm{~m} / \mathrm{s}$, so the particle phase is more floating. Consequently, the particle contact with the $\mathrm{CSO}$ is reduced, which will affect the degumming process. 


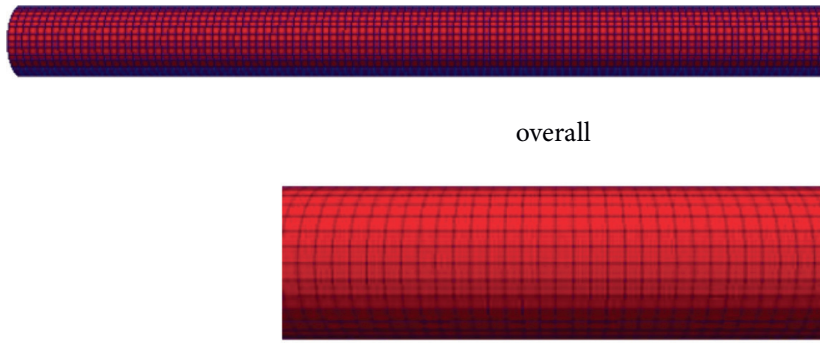

outer wall

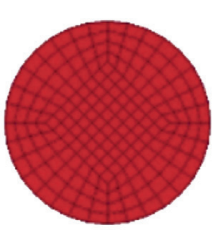

Top and bottom walls

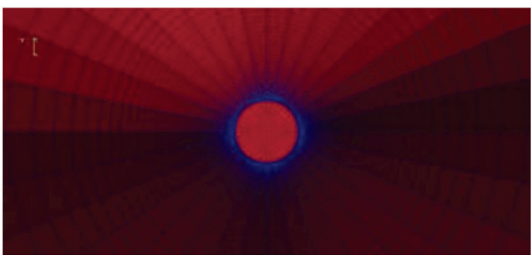

inner wall

Figure 1: Mesh partition.

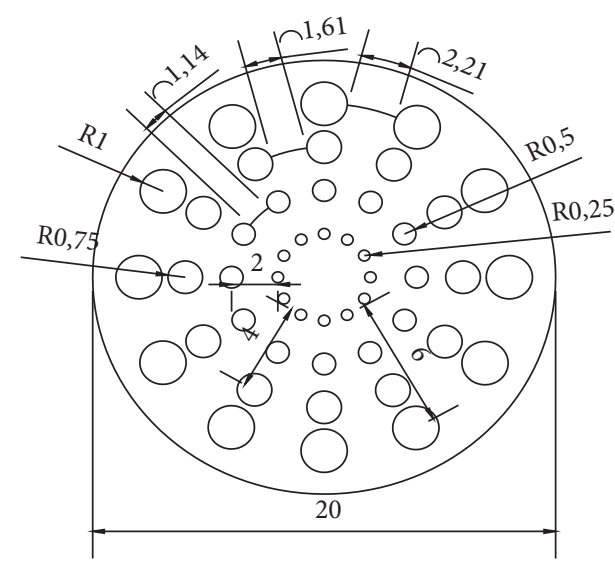

(a)

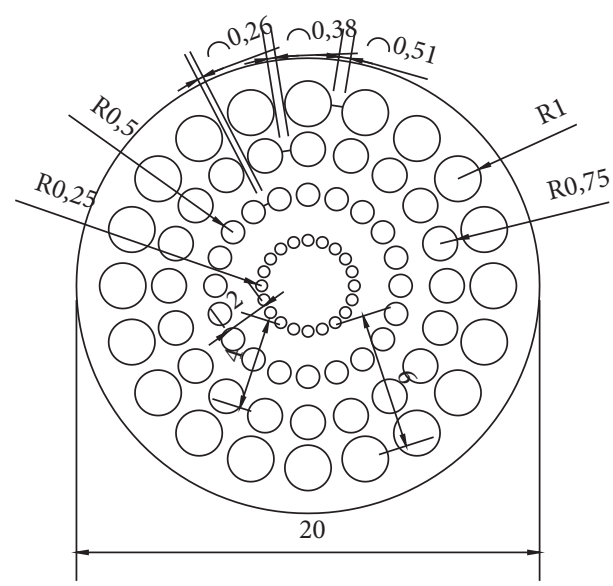

(c)

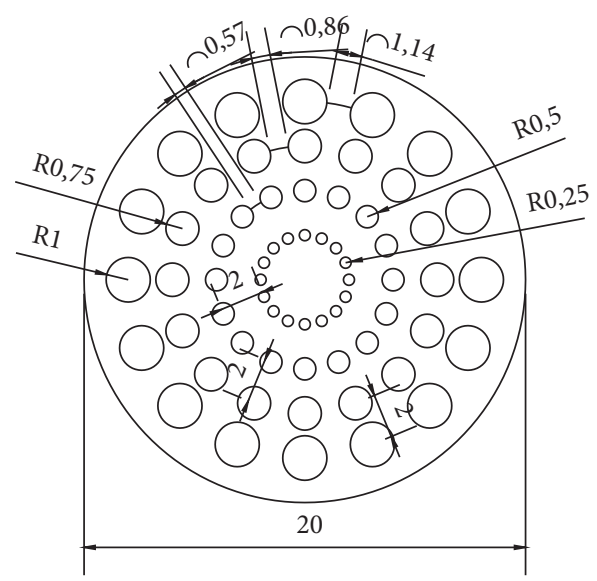

(b)

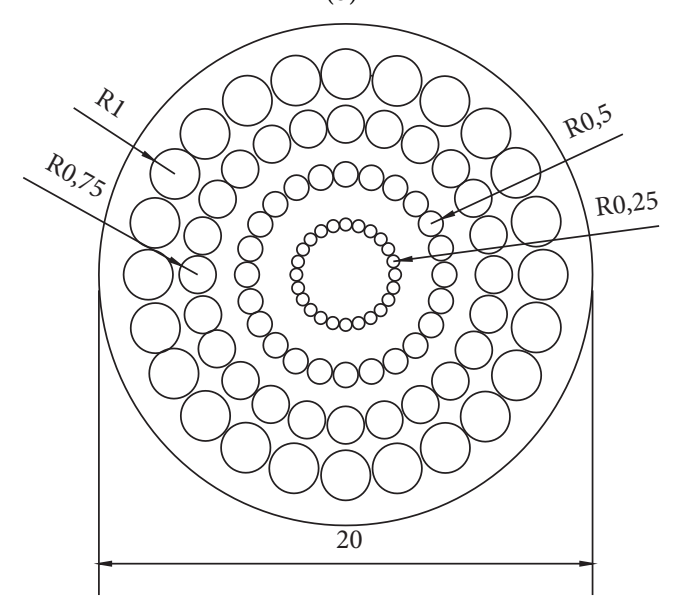

(d)

Figure 2: Different types of distribution board; adjust the opening rate separately: (a) $22.5 \%$, (b) $30.0 \%$, (c) $37.5 \%$, and (d) $45.0 \%$. 
TABLE 2: The relationship between current and magnetic field intensity.

\begin{tabular}{lllll}
\hline I/A & 0 & 0.90 & 1.80 & 2.40 \\
\hline B/Gs & 0 & 107 & 203 & 298 \\
\hline H/T & 0 & 0.01 & 0.02 & 0.03 \\
\hline
\end{tabular}

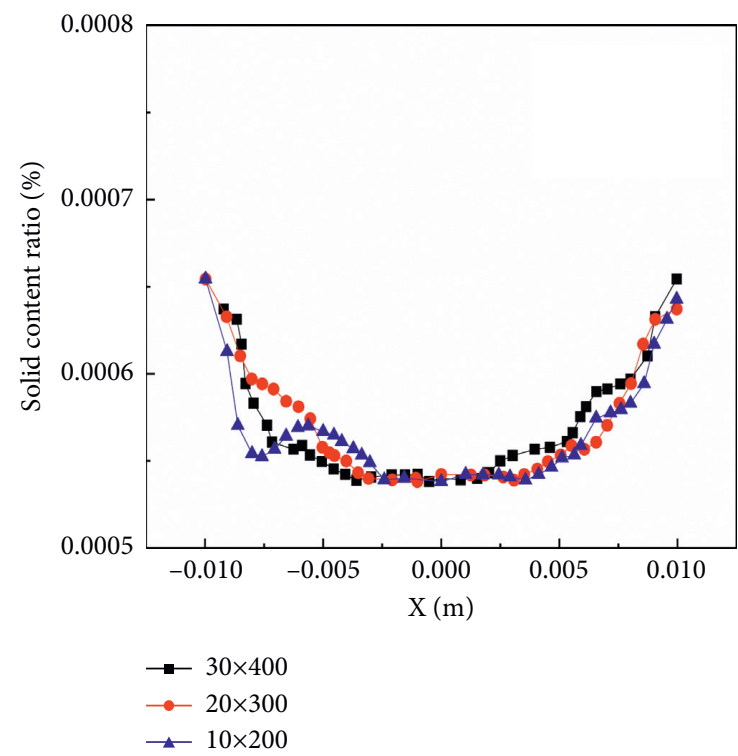

(a)

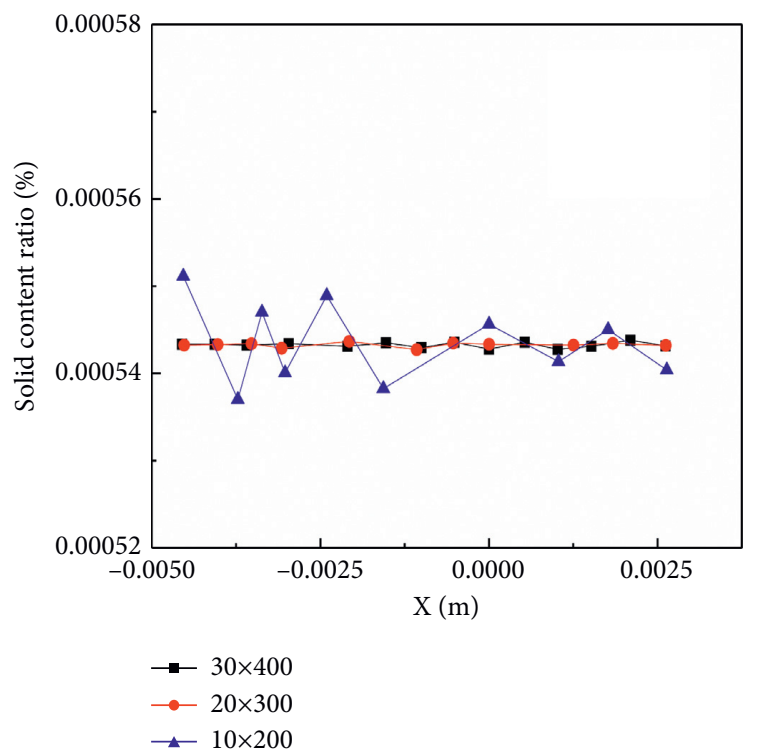

(b)

Figure 3: Effect of grid scale on nanomagnetic enzyme distribution. (a) Distribution of solid content of nanomagnetic enzyme particles at different mesh scales of MFB whole. (b) Distribution of solid content of nanomagnetic enzyme particles at different mesh scales of MFB local.

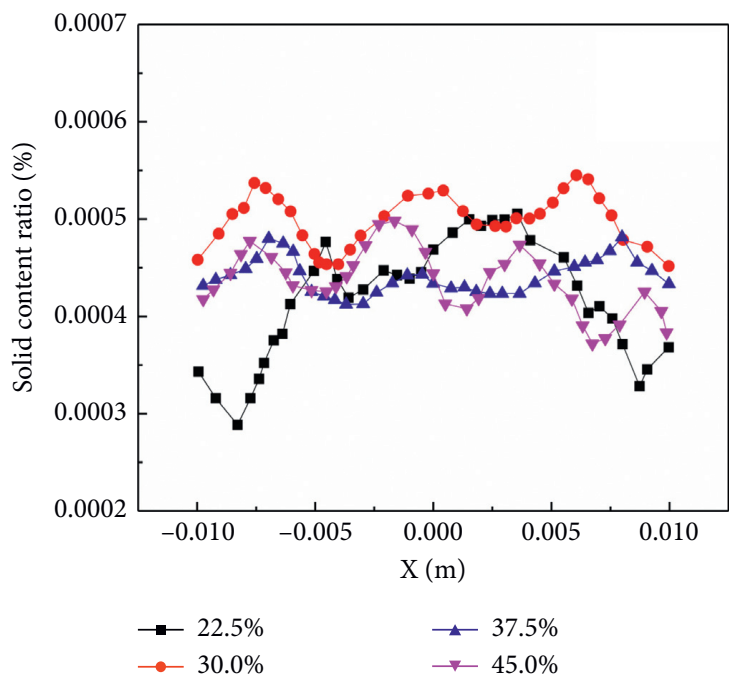

(a)

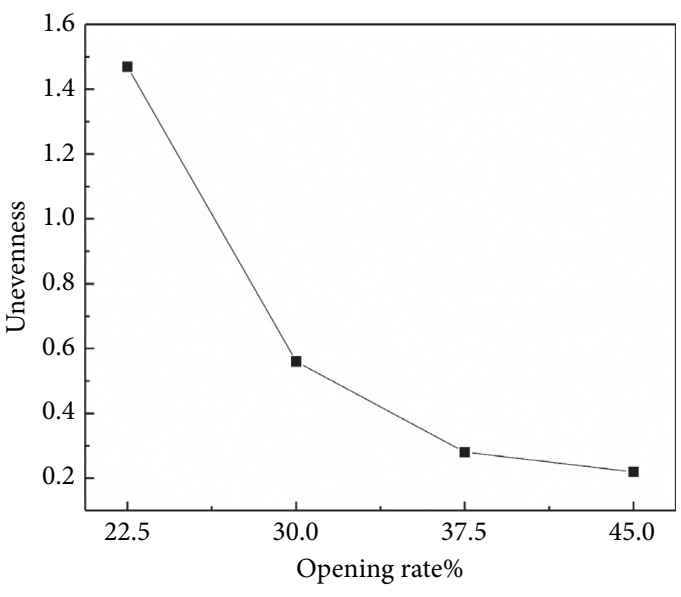

(b)

FIGURE 4: Influence of the porosity of the multiwell plate on the distribution of nanomagnetic enzymes. (a) Different multiorifice of magnetic particle density distribution of enzyme. (b) Different multiorifice when the magnetic particle density distribution of enzyme.

When the flow rate of the $\mathrm{CSO}$ increases to $0.1 \mathrm{~m} / \mathrm{s}$, the graph shows that the range of particle speed changes fluctuates significantly, showing turbulence. This may be due to the increase in the CSO speed, which causes the force distribution of the nanomagnetic enzyme to be uneven, which does not show a good fluidization effect. In summary, the selection of $0.01 \mathrm{~m} / \mathrm{s}$ for the flow rate of the CSO has the finest driving effect on the nanomagnetic enzyme. 


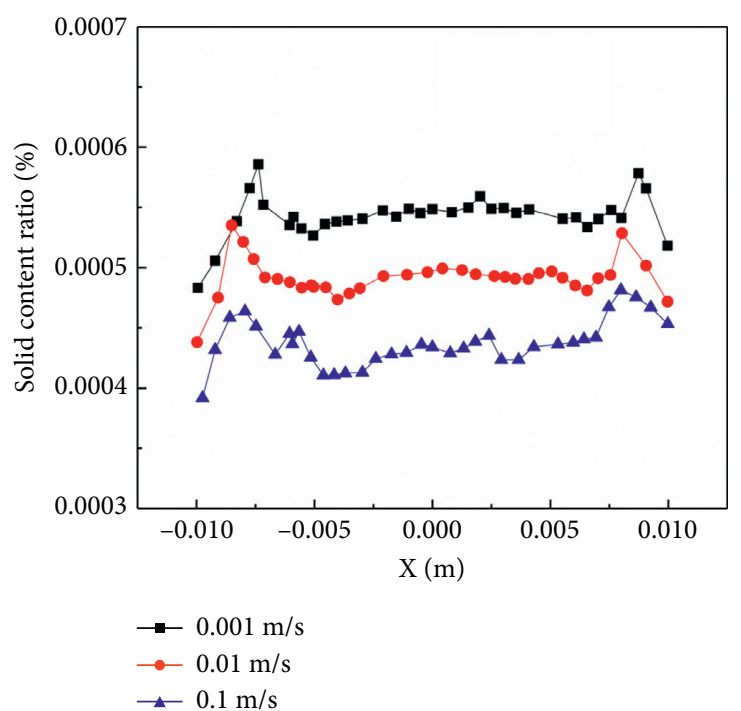

(a)

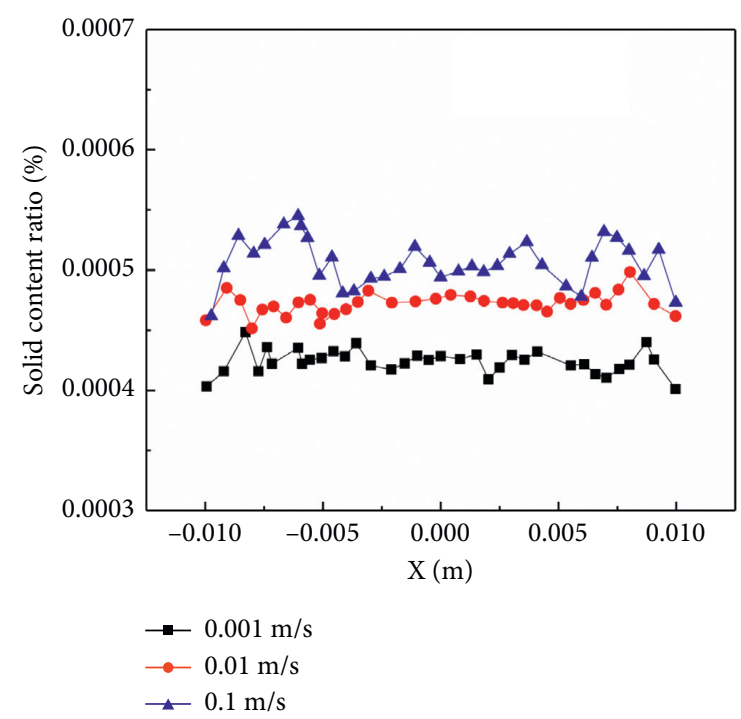

(b)

FIGURE 5: Influence of crude oil flow velocity on the distribution of nanomagnetic enzymes. (a) Solids holdup of nanomagnetic enzyme particles at the height of $75 \mathrm{~mm}$. (b) Solids holdup of nanomagnetic enzyme particles at the height of $225 \mathrm{~mm}$.

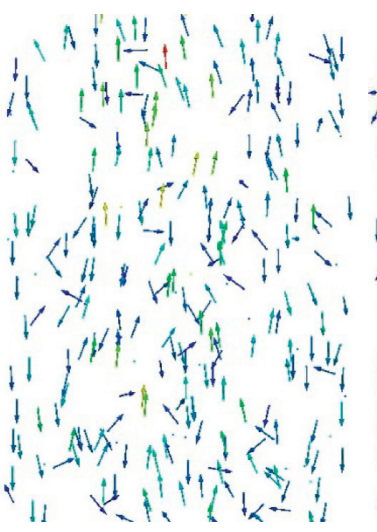

(a)

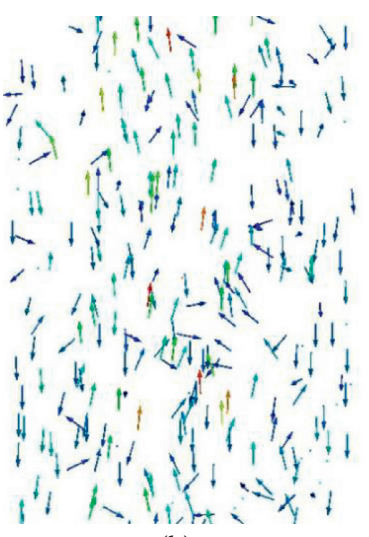

(b)

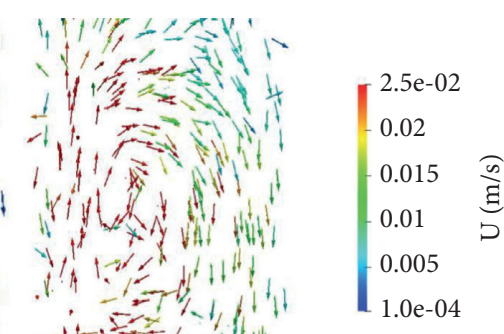

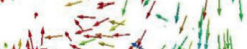

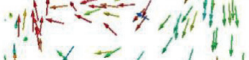

(c)

FIGURE 6: Particle velocity vector diagram of different flow velocity of CSO. (a) $0.001 \mathrm{~m} / \mathrm{s}$. (b) $0.01 \mathrm{~m} / \mathrm{s}$. (c) $0.1 \mathrm{~m} / \mathrm{s}$.

3.5. Effect of Magnetic Field Strength on Bed Pressure. To study the influence of magnetic field strength on the movement state of nanomagnetic enzyme particles, the stability of the bed inside the MFB device needs to be studied firstly. The pressure at the bottom of the bed can clearly show the effect of different magnetic field strength on the bottom of the bed. The flow rate of the CSO phase was $0.01 \mathrm{~m} / \mathrm{s}$, the porosity of the perforated plate was $37.5 \%$, and the magnetic field intensity range was $0 \sim 0.03 \mathrm{~T}$ [34]. The physical time was $4,6,8$, and $10 \mathrm{~s}$. The strength of the magnetic field plays a key role in the distribution of the nanomagnetic enzyme particles. In simulation, we need to increase the magnetic force of the interaction between the nanomagnetic enzyme particles, so that the particles aggregate to form a state of tiny magnetic chains, so that the liquid can easily pass through the magnetic chains. The voids flow through which is more conducive to the degumming reaction [35-37]. When particles exist in the state of tiny magnetic chains, they will be subjected to greater gravity to settle, which will also increase the pressure at the bottom of the bed. According to Figure 7, there is no magnetic field, the phase-to-phase coupling effect of the nanomagnetic enzyme phase is small, and the effect of the velocity of the oil flow is large. Thus, the effect on the bottom pressure of the bed is small. The pressure at the bottom of the bed increases with the increase of the field strength. When the field strength is $0.02-0.03 \mathrm{~T}$, the pressure at the bottom of the bed decreases with the increase of the field strength.

3.6. Effect of Magnetic Field Intensity on the Distribution of Nanomagnetic Enzymes. When the magnetic field strength is stable, the distribution of nanomagnetic enzymes shows a high distribution state, so it is necessary to study the distribution of nanomagnetic enzymes at different field strengths. The flow rate of the CSO is $0.01 \mathrm{~m} / \mathrm{s}$, the opening 

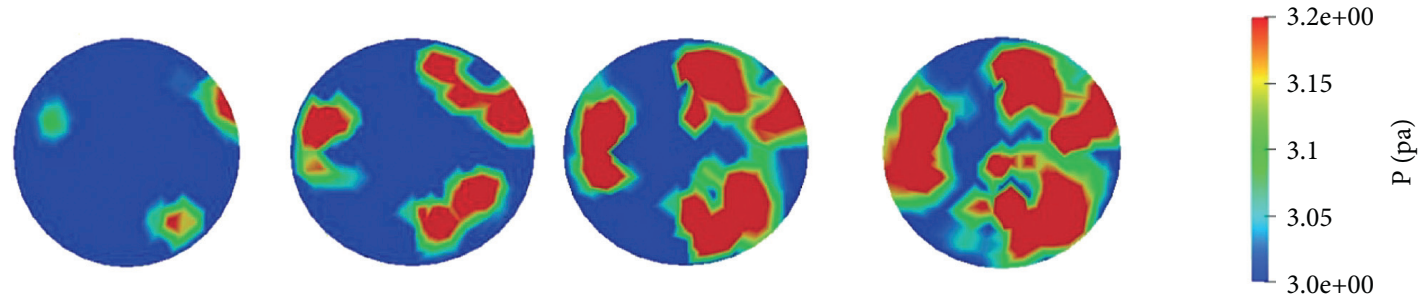

$0 \mathrm{~T}$
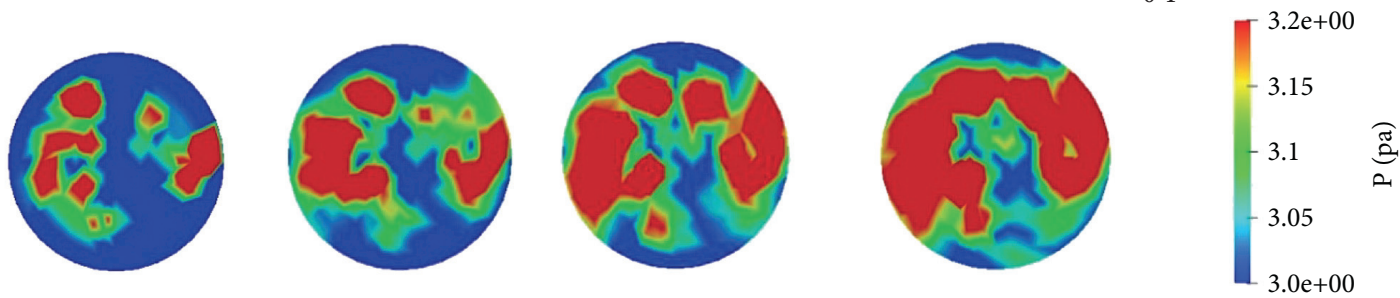

$0.01 \mathrm{~T}$
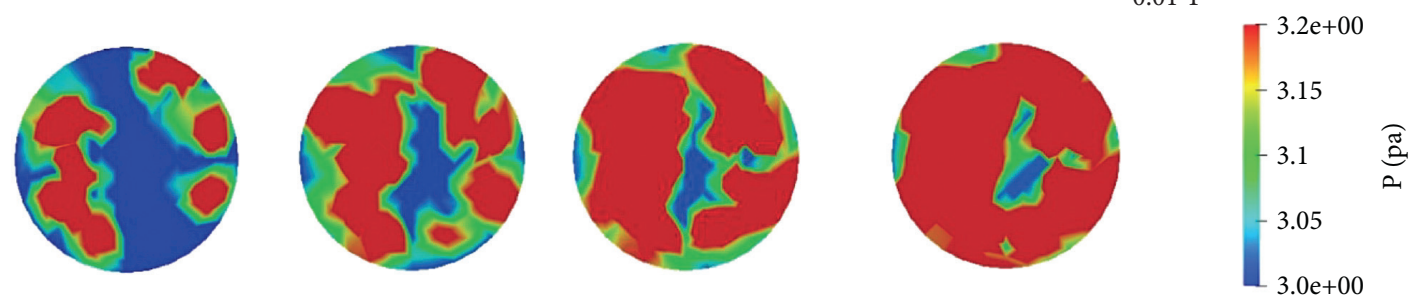

$0.02 \mathrm{~T}$

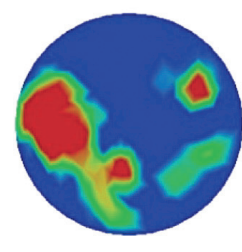

$4 \mathrm{~s}$

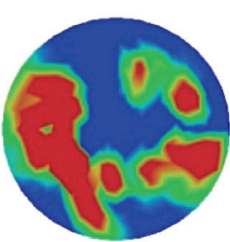

$6 s$

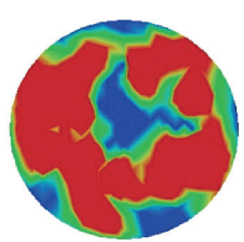

$8 \mathrm{~s}$

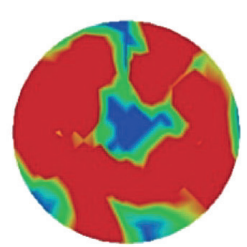

$10 \mathrm{~s}$

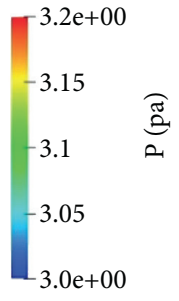

$0.03 \mathrm{~T}$

FIGURE 7: Effect of magnetic field on the bed pressure nephogram.

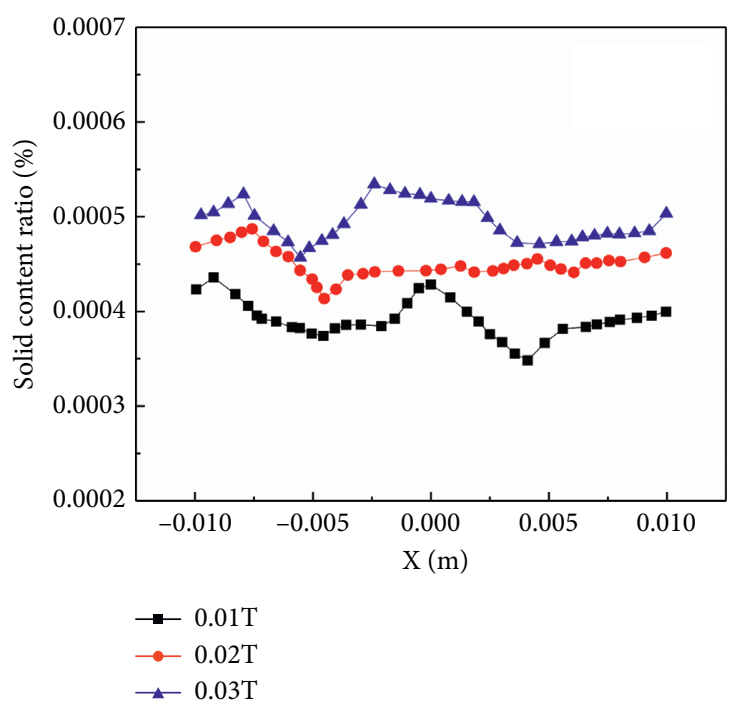

(a)

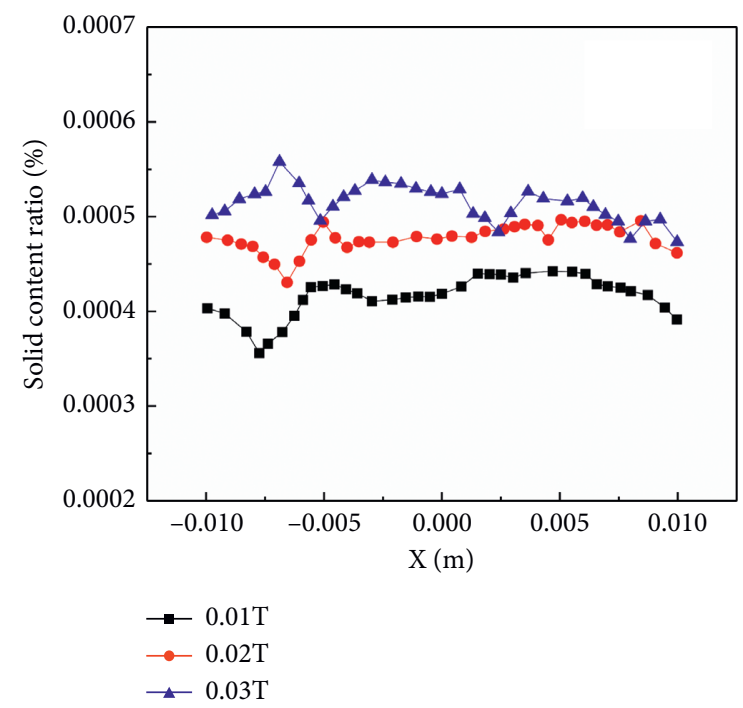

(b)

FIGURE 8: Effect of magnetic field intensity on the distribution of nanomagnetic enzymes. (a) Distribution of solid content at an axial height of $75 \mathrm{~mm}$ under different magnetic field strength (b) Distribution of solid content at an axial height of $225 \mathrm{~mm}$ under different magnetic field strength. 
TABLE 3: Degumming effect of nanomagnetic enzyme particles.

\begin{tabular}{lcc}
\hline Parameter & Intermittent degumming & Multistage cyclic degumming \\
\hline Heating water $(\mathrm{mL} / \mathrm{kg}$ oil) & 30 & 30 \\
Temperature $\left({ }^{\circ} \mathrm{C}\right)$ & 60 & 62 \\
Stirring speed $(\mathrm{r} / \mathrm{min})$ & 60 & - \\
Time $(\mathrm{h})$ & 2.5 & 2 \\
Relative enzyme activity after degumming for $2.5 \mathrm{~h}$ & $90 \%$ & $97 \%$ \\
pH & 7.3 & 7.5 \\
Nanomagnetic enzyme addition amount $(\mathrm{g} / \mathrm{kg})$ & 0.11 & 0.10 \\
Phosphorus content $(\mathrm{mg} / \mathrm{kg})$ & $64.82 \pm 0.2$ & $55.73 \pm 0.1$ \\
$1,2-$ DAG $(\%)$ & $1.06 \pm 0.02$ & $1.42 \pm 0.01$ \\
\hline
\end{tabular}

rate is $37.5 \%$, the magnetic field intensity range is $0.01 \mathrm{~T}-0.03 \mathrm{~T}$, and the data are collected at the axial height of $75 \mathrm{~mm}$ and $225 \mathrm{~mm}$ from the porous plate. The simulation results are shown in Figures 8(a) and 8(b). According to Figures 8 (a) and 8(b), it is not difficult to find that, with the increase of the field strength, the nanomagnetic enzyme distribution state distribution gradually stabilizes, and the values of the nanomagnetic enzyme content at different axial heights in the MFB device are uniform. Under the magnetic field, the fluidization quality of the nanomagnetic enzyme particles is significantly improved. At the same time, increasing the magnetic field can also effectively suppress the expansion effect of the bed and reduce the expansion height of the bed [38]. Consequently, the bed enters a more stable state of magnetic fluidization. The simulation results show that when the magnetic field strength is $0.02 \mathrm{~T}$, the fluctuation range of the curve of the nanomagnetic enzyme distribution state is small, indicating that the particle phase can form a fluidized state stably at this time, and therefore, the optimal magnetic field strength is $0.02 \mathrm{~T}$.

3.7. Study on the Effect of Nanomagnetic Enzyme on Degumming of CSO. The results of cyclic degumming of nanomagnetic enzyme particles in a batch reaction system and a multistage MFB are shown in Table 3. The degumming time was shortened by $0.5 \mathrm{~h}$, the relative enzyme activity was $7 \%$ higher at the same time, and the output of neutral oil was significantly improved. In a MFB reaction system, under the optimal reaction conditions, the phosphorus content in soybean degummed oil can be reduced to $55.73 \mathrm{mg} / \mathrm{kg}$. This indicates that, under the action of magnetic field, nanomagnetic enzyme particles are evenly distributed in a fluidized state in a MFB to form a ring-core flow [39-41]. These optimal reaction conditions promoted the dispersion of nanomagnetic enzyme particles in the oil phase and the water phase, thereby forming a more uniform reaction system.

\section{Conclusion}

In this experiment, the theoretical parameters of the optimal motion state of nanomagnetic enzyme in MFB were simulated by the computer. Based on the simulated theoretical parameters, the nanomagnetic enzyme was applied to the multistage circulating MFB for CSO degumming. The effects of mesh size, opening rate, crude oil flow velocity, and magnetic field intensity on the particle movement and the stability of the MFB were studied. It was found that, under the optimal parameters, the degumming time was shortened, and the mechanical damage of nanomagnetic enzyme was reduced. The results showed that compared with intermittent degumming, multistage cyclic degumming with nanomagnetic enzyme in the magnetic fluidized bed did not need mechanical stirring. The activity loss rate of nanomagnetic enzyme in multistage MFB was reduced. The amount of nanomagnetic enzyme needed was reduced, the phosphorus content was reduced, and the 1,2-DAG content was increased. The nanomagnetic enzyme was dispersed uniformly under the magnetic force forming core-annular flow law. This study provides a theoretical basis for the continuous removal of phospholipids in crude soybean oil by nanomagnetic enzyme particles in the MFB.

\section{Data Availability}

Data are available within the article and its supplementary materials.

\section{Conflicts of Interest}

The authors declare that they have no conflicts of interest.

\section{Acknowledgments}

This work was supported by the research and development projects of Heilongjiang Provincial Education Department (TSTAU-R 2018010).

\section{Supplementary Materials}

Supplementary Figure 1. Process diagram of liquid-solid two-phase magnetic fluidized bed degumming. Supplementary Figure 2. Magnetic fluidized bed (MFB) model. Supplementary Figure 3. Magnetic interaction between nanomagnetic enzyme particles. (Supplementary Materials)

\section{References}

[1] Y. Qu, L. Sun, X. Li et al., "Enzymatic degumming of soybean oil with magnetic immobilized phospholipase A2," Lebensmittel-Wissenschaft \& Technologie, vol. 73, pp. 290-295, 2016.

[2] D. L. Lamas, G. H. Crapiste, and D. T. Constenla, "Changes in quality and composition of sunflower oil during enzymatic 
degumming process," Lebensmittel-Wissenschaft und -Technologie- Food Science and Technology, vol. 58, no. 1, pp. 71-76, 2014.

[3] M. S. Piel, G. H. J. Peters, and J. Brask, "Chemoenzymatic synthesis of fluorogenic phospholipids and evaluation in assays of phospholipases A, C and D," Chemistry and Physics of Lipids, vol. 202, pp. 49-54, 2017.

[4] S. A. Ansari and Q. Husain, "Potential applications of enzymes immobilized on/in nano materials: a review," Biotechnology Advances, vol. 30, no. 3, pp. 512-523, 2012.

[5] W. S. Galvão, B. B. Pinheiro, L. R. B. Golçalves et al., "Novel nanohybrid biocatalyst: application in the kinetic resolution of secondary alcohols," Journal of Materials Science, vol. 53, no. 20, pp. 14121-14137, 2018.

[6] Y.-H. Chen, M.-C. Chi, T.-F. Wang, J.-C. Chen, and L.-L. Lin, "Preparation of magnetic nanoparticles and their use for immobilization of C-terminally lysine-tagged Bacillus sp. TS$23 \alpha$-amylase," Applied Biochemistry and Biotechnology, vol. 166, no. 7, pp. 1711-1722, 2012.

[7] S. Shafiee, M. H. McCay, and S. Kuravi, "Effect of magnetic fields on thermal conductivity in a ferromagnetic packed bed," Experimental Thermal and Fluid Science, vol. 86, pp. 160-167, 2017.

[8] L. Mosafa, M. Moghadam, and M. Shahedi, "Papain enzyme supported on magnetic nanoparticles: preparation, characterization and application in the fruit juice clarification," Chinese Journal of Catalysis, vol. 34, no. 10, pp. 1897-1904, 2013.

[9] Y.-J. Gu, M.-L. Zhu, Y.-L. Li, and C.-H. Xiong, "Research of a new metal chelating carrier preparation and papain immobilization," International Journal of Biological Macromolecules, vol. 112, pp. 1175-1182, 2018.

[10] R. Margesin, G. Feller, M. Hämmerle, U. Stegner, and F. Schinner, "A colorimetric method for the determination of lipase activity in soil," Biotechnology Letters, vol. 24, no. 1, pp. 27-33, 2002.

[11] J. B. Joshi and V. V. Ranade, "Computational fluid dynamics for designing process equipment: expectations, current status, and path forward," Industrial \& Engineering Chemistry Research, vol. 42, no. 6, pp. 1115-1128, 2003.

[12] O. Hadj, A. Goodarz, and B. McLaughlin John, "Dispersion and deposition of Brownian particles from point sources in a simulated turbulent channel flow," Journal of Colloid and Interface Science, vol. 147, no. 1, 1991.

[13] A. Li and G. Ahmadi, "Dispersion and deposition of spherical particles from point sources in a turbulent channel flow," Aerosol Science and Technology, vol. 16, no. 4, 1992.

[14] M. Carozza, J. Kristensen, and A. Passarelli di Napoli, "On the validity of the Euler-Lagrange system," Communications on Pure and Applied Analysis, vol. 14, no. 1, 2014.

[15] N. Mircea, "From Euler-Lagrange equations to canonical nonlinear connections," Archivum Mathematicum, vol. 42, no. 3, 2006.

[16] A. SenGupta, B. Santillana, S. Sridhar, and M. Auinger, "Transient effect of fluid flow on dendrite growth direction in binary Fe-C alloys using phase field in OpenFOAM," Journal of Occupational Medicine, vol. 71, no. 11, pp. 3876-3884, 2019.

[17] C. Kunkelmann and P. Stephan, "CFD simulation of boiling flows using the volume-of-fluid method within OpenFOAM," Numerical Heat Transfer, Part A: Applications, vol. 56, no. 8, pp. 631-646, 2009.

[18] Y. Jiang, J. Du, H. Tang et al., "Synthesis and application of nanomagnetic immobilized phospholipase C," Journal of Chemistry, vol. 2019, Article ID 5951793, 9 pages, 2019.
[19] AOCS, Official Methods and Recommended Practices of the AOCS, American Oil Chemists' Society Champaign, Urbana, IL, USA, 1997.

[20] X. Jiang, M. Chang, Q. Jin, and X. Wang, “Application of phospholipase $\mathrm{A} 1$ and phospholipase $\mathrm{C}$ in the degumming process of different kinds of crude oils," Process Biochemistry, vol. 50, no. 3, pp. 432-437, 2015.

[21] P. Ravasi, M. Braia, F. Eberhardt et al., "High-level production of Bacillus cereus phospholipase C in Corynebacterium glutamicum," Journal of Biotechnology, vol. 216, pp. 142-148, 2015.

[22] D. Yu, Y. Wang, B. Yu et al., "Numerical simulation and application of nanomagnetic enzyme in a liquid-solid magnetic fluidized bed," Process Biochemistry, vol. 75, pp. 121-129, 2018.

[23] D. Gidaspow, R. Bezburuah, and J. Ding, Hydrodynamics of Circulating Fluidized Beds: Kinetic Theory Approach, Illinois Institute of Technology, Chicago, IL, USA, 1991.

[24] P. Talebizadehsardari, R. Hassan, G. Ahmadi, M. A. Moghimi, K. Inthavong, and M. Esapour, "Nano-particle deposition in axisymmetric annular pipes with thread," Particulate Science \& Technology, vol. 38, no. 7, 2020.

[25] P. Talebizadeh, H. Rahimzadeh, G. Ahmadi, R. Brown, and K. Inthavong, "Time history of diesel particle deposition in cylindrical dielectric barrier discharge reactors," Journal of Nanoparticle Research, vol. 18, no. 12, 2016.

[26] P. Talebizadeh Sardari, R. Hassan, G. Ahmadi, and D. Giddings, "Nano-particle deposition in the presence of electric field," Journal of Aerosol Science, vol. 126, 2018.

[27] A. Darras, E. Opsomer, N. Vandewalle, and G. Lumay, "Effect of volume fraction on chains of superparamagnetic colloids at equilibrium," The European Physical Journal E, vol. 42, no. 9, 2019.

[28] L. Zhou, C. Han, L. Bai, W. Li, M. Emam, and W. Shi, "CFDDEM bidirectional coupling simulation and experimental investigation of particle ejections and energy conversion in a spouted bed," Energy, vol. 211, 2020.

[29] M. A. El-Emam, L. Zhou, W. Shi, and C. Han, "Performance evaluation of standard cyclone separators by using CFD-DEM simulation with realistic bio-particulate matter," Powder Technology, vol. 385, pp. 357-374, 2021.

[30] M. G. Jang, D. K. Kim, S. C. Park, J. S. Lee, and S. W. Kim, "Biodiesel production from crude canola oil by two-step enzymatic processes," Renewable Energy, vol. 42, pp. 99-104, 2012.

[31] I. Hulme, E. Clavelle, L. van der Lee, and A. Kantzas, "CFD modeling and validation of bubble properties for a bubbling fluidized bed," Industrial \& Engineering Chemistry Research, vol. 44, no. 12, pp. 4254-4266, 2005.

[32] J. T. Cornelissen, F. Taghipour, R. Escudié, N. Ellis, and J. R. Grace, "CFD modelling of a liquid-solid fluidized bed," Chemical Engineering Science, vol. 62, no. 22, pp. 6334-6348, 2007.

[33] S. Wang, X. Wang, R. Wang et al., "Simulations of flow behavior of particles in a liquid-solid fluidized bed using a second-order moments model," Powder Technology, vol. 302, pp. 21-32, 2016.

[34] K. Parekh, J. Patel, and R. V. Upadhyay, "Temperature dependent acoustic properties of temperature sensitive magnetic fluid subjected to magnetic field," Journal of Molecular Liquids, vol. 248, pp. 569-576, 2017.

[35] H. Zhenghua, L. Xiang, L. Huilin et al., "Numerical simulation of particle motion in a gradient magnetically assisted fluidized bed," Powder Technology, vol. 203, no. 3, pp. 555-564, 2010. 
[36] S. Wang, Y. Shen, Y. Ma et al., "Study of hydrodynamic characteristics of particles in liquid-solid fluidized bed with uniform transverse magnetic field," Powder Technology, vol. 245, pp. 314-323, 2013.

[37] S. Wang, Z. Sun, X. Li, J. Gao, X. Lan, and Q. Dong, "Simulation of flow behavior of particles in liquid-solid fluidized bed with uniform magnetic field," Powder Technology, vol. 237, pp. 314-325, 2013.

[38] S. Wang, J. Sun, Q. Yang, Y. Zhao, J. Gao, and Y. Liu, "Numerical simulation of flow behavior of particles in an inverse liquid-solid fluidized bed," Powder Technology, vol. 261, pp. 14-21, 2014.

[39] Q. Zhu, H. Li, Q. Zhu, J. Li, and Z. Zou, "Hydrodynamic study on magnetized fluidized beds with Geldart-B magnetizable particles," Powder Technology, vol. 268, pp. 48-58, 2014.

[40] J. Hristov, "Magnetically assisted gas-solid fluidization in a tapered vessel: first report with observations and dimensional analysis," The Canadian Journal of Chemical Engineering, vol. 86, no. 3, pp. 470-492, 2008.

[41] G. H. dos Santos and N. Mendes, "Analysis of numerical methods and simulation time step effects on the prediction of building thermal performance," Applied Thermal Engineering, vol. 24, no. 8-9, pp. 1129-1142, 2004. 